Accepted refereed manuscript of:

Amrein MA, Rackow P, Inauen J, Radtke T \& Scholz U (2017) The role of Compensatory Health Beliefs in eating behavior change: A mixed method study. Appetite, 116, pp. 1-10. DOI: https://doi.org/10.1016/j.appet.2017.04.016

(C) 2017, Elsevier. Licensed under the Creative Commons Attribution-NonCommercialNoDerivatives 4.0 International http://creativecommons.org/licenses/by-nc-nd/4.0/

\title{
The role of Compensatory Health Beliefs in eating behavior change: A mixed method study
}

Melanie A. Amrein, Corresponding author

Department of Psychology, University of Zurich, Zurich, Switzerland

Pamela Rackow

Health Psychology, Institute of Applied Health Sciences, University of Aberdeen, Aberdeen, Scotland

Jennifer Inauen

Department of Environmental Social Sciences, Eawag - Swiss Federal Institute of Aquatic Science \& Technology, Duebendorf, Switzerland

Department of Psychology, Columbia University, New York, USA

Theda Radtke

Department of Psychology, University of Zurich, Zurich, Switzerland

Urte Scholz

Department of Psychology, University of Zurich, Zurich, Switzerland

\section{Author Note}

Correspondence concerning this article should be addressed to Melanie A. Amrein, Department of Psychology, University of Zurich, Binzmühlestrasse 14, 8050 Zurich, Switzerland, phone: +41 4463572 60, email: melanie.amrein@uzh.ch 


\begin{abstract}
Compensatory Health Beliefs (CHBs), defined as beliefs that an unhealthy behavior can be compensated for by engaging in another healthy behavior, are assumed to hinder health behavior change. The aim of the present study was to investigate the role of CHBs for two distinct eating behaviors (increased fruit and vegetable consumption and eating fewer unhealthy snacks) with a mixed method approach. Participants $(N=232$, mean age $=27.3$ years, $76.3 \%$ women) were randomly assigned to a fruit and vegetable or an unhealthy snack condition. For the quantitative approach, path models were fitted to analyze the role of CHBs within a social-cognitive theory of health behavior change, the Health Action Process Approach (HAPA). With a content analysis, the qualitative approach investigated the occurrence of CHBs in smartphone chat groups when pursuing an eating goal. Both analyses were conducted for each eating behavior separately. Path models showed that CHBs added predictive value for intention, but not behavior over and above HAPA variables only in the unhealthy snack condition. CHBs were significantly negatively associated with intention and action planning. Content analysis revealed that people generated only a few CHB messages. However, CHBs were more likely to be present and were also more diverse in the unhealthy snack condition compared to the fruit and vegetable condition. Based on a mixed method approach, this study suggests that CHBs play a more important role for eating unhealthy snacks than for fruit and vegetable consumption.
\end{abstract}

Keywords: Compensatory Health Beliefs, Unhealthy snacks, Fruit and vegetable consumption, Health Action Process Approach, Smartphone chat groups. 


\section{Introduction}

Following a healthy diet is linked to better health. For example, fruit and vegetable consumption is associated with a lower risk of stroke (He, Nowson, \& MacGregor, 2006; Hu, Huang, Wang, Zhang, \& Qu, 2014) and type 2 diabetes (Wang, Fang, Gao, Zhang, \& Xie, 2016). In contrast, it has been estimated that inadequate fruit and vegetable consumption is responsible for 2.6 million deaths per year worldwide (Lock, Pomerleau, Causer, Altmann, \& McKee, 2005). Similarly, high sugar and fat intake can increase blood glucose, which is a main risk factor for heart attack, stroke and obesity (World Health Organization, 2014). Obesity in turn is associated with cardiovascular disease, type 2 diabetes, cancer, osteoarthritis and psychological illnesses such as depression (Dixon, 2010). As obesity rates are increasing worldwide (Doytch, Dave, \& Kelly, 2016), understanding mechanisms to promote healthy eating is crucial for prevention.

Healthy eating comprises several different behaviors. The World Health Organization (2014) recommends limiting the intake of sugar or fat, for example by reducing the amount of unhealthy snacks, and increasing the numbers of fruits and vegetables consumed. These two eating behaviors represent different forms of behavioral change: Eating more fruits and vegetables requires striving for and promoting a healthy behavior. In contrast, eating fewer unhealthy snacks requires reducing and inhibiting an unhealthy behavior. There is evidence that different determinants underlie the prediction of these eating behaviors (Allom \& Mullan, 2014). Thus, investigating different eating behaviors and their relevant predictors separately might be of special advantage to promote a healthy diet.

\section{Compensatory Health Beliefs and health behavior change}

Following a healthy diet can be difficult, and only a few individuals can successfully change their eating behavior in the long run (e.g. Wing \& Phelan, 2005). Having a long-term goal for healthy eating (e.g. eating less sugar) but then getting the offer of a delicious cake, 
individuals may experience a motivational conflict and cognitive dissonance (Festinger, 1962) resulting in a bad feeling. It is assumed that individuals activate Compensatory Health Beliefs (CHBs; Knäuper, Rabiau, Cohen, \& Patriciu, 2004) to mitigate such unpleasant states (Rabiau, Knäuper, \& Miquelon, 2006) and to justify indulgence (Rabiau et al., 2006). CHBs are beliefs that the negative consequences of an unhealthy behavior (e.g. eating chocolate) can be compensated for with the assumed positive effects of an executed healthy behavior (e.g. exercise). Thus, the activation of CHBs can lower intentions to resist the desire for unhealthy food (Knäuper et al., 2004), which in turn can help to explain the occurrence of unhealthy eating (Kronick, Auerbach, Stich, \& Knäuper, 2011) despite the intention to eat healthily. There is evidence that CHBs are negatively associated with intention for different health behaviors such as physical activity (Berli, Loretini, Radtke, Hornung, \& Scholz, 2014), smoking (Berli et al., 2014; Fleig et al., 2015; Radtke, Scholz, Keller, \& Hornung, 2012) and unhealthy eating (Radtke, Inauen, Rennie, Orbell, \& Scholz, 2014).

To provide a stronger test for the predictive value of CHBs in eating behavior, recent studies have investigated CHBs as an additional predictor to a widely established health behavior model: the Health Action Process Approach (HAPA; Berli et al., 2014; Fleig et al., 2015; Radtke et al., 2012; Radtke, Kaklamanou, Scholz, Hornung, \& Armitage, 2014; Schwarzer, 2008; Storm et al., 2016). The HAPA distinguishes between a motivational phase of intention formation and a volitional phase of translating the intention into behavior. The motivational phase includes self-efficacy, outcome expectancy, and risk awareness to predict intention. The volitional phase includes action planning and action control as predictors for behavior and as mediating constructs between intention and behavior (Sniehotta, Scholz, \& Schwarzer, 2005). However, recent study results on CHBs and HAPA point in different directions regarding the predictive value of $\mathrm{CHBs}$ for intention and behavior. On the one side, no relation was found for fruit and vegetable consumption and the intention to eat fruits and 
vegetables (Storm et al., 2016). A further study showed no relation between CHBs and the intention and behavior for fat and sugar intake (Radtke et al., 2014). On the other side, there is evidence for a positive relation between CHBs and calorie intake (Kronick et al., 2011; Radtke et al., 2014) and for a negative relation between diet-specific CHBs and intention to diet (Fleig et al., 2015). In addition to the direct effects of CHBs on intention and behavior, secondary analyses were conducted to investigate whether individuals with higher CHBs show a lower application of action planning and action control (Fleig et al., 2015; Radtke et al., 2012; Radtke et al., 2014).

Overall, research on the role of CHBs in health behavior change shows mixed results for different eating behaviors. No study so far has investigated the role of CHBs for different behaviors simultaneously in the same health domain. To bridge this gap, this study investigated the role of $\mathrm{CHBs}$ in eating behavior change by making a distinction between two different eating behaviors: increasing fruit and vegetable consumption and avoiding unhealthy snacks.

\section{Situation-specific CHBs to excuse unhealthy eating}

To date, most studies have assessed $\mathrm{CHBs}$ with generally formulated items in order to capture overall beliefs about compensation (e.g. Ernsting, Schwarzer, Lippke, \& Schneider, 2013). As hypothesized from the CHBs model (Rabiau et al., 2006), such beliefs arise in situations where people are facing a motivational conflict. Thus, a recent study about snacking behavior has focused on state CHBs, which are situation-specific and address a specific behavior (Radtke et al., 2014). The authors have found that exercise-related state CHBs (e.g. "I do not need to keep myself from snacking, because I will engage in physical activity later on today") are positively associated with calories consumed. However, state CHBs were only marginally predictive for snacking behavior and it is assumed that people may have different thoughts about and excuses for their unhealthy behavior (Kaklamanou, 
Armitage, \& Jones, 2013; Radtke et al., 2014). Another approach to examine such excuses or justifications for unhealthy eating is asking participants to recall situations where they have indulged in unhealthy eating and to report their thoughts (Taylor, Webb, \& Sheeran, 2014; Verhoeven, Adriaanse, De Vet, Fennis, \& De Ridder, 2015). Using this approach, however, retrospective and response biases can occur. No study so far has focused on situations where people indulge in unhealthy behavior to investigate situation-specific CHBs. Further, previous studies about excuses have assessed unhealthy eating with snacking behavior only. Research about excuses for low fruit and vegetable consumption is missing. As eating behaviors underlie different forms of behavior change, we assume that situation-specific CHBs depend upon the health behavior people engage in. Therefore, this study aims to examine situation-specific CHBs for two eating behaviors: fruit and vegetable consumption and eating unhealthy snacks.

To investigate situations in which people think about how to compensate for their unhealthy behavior, a real-life setting should be analyzed. It has been shown that individuals seek the internet for health-related information (Rice, 2006) and that they are using forums or chat groups to communicate with others about health to feel better able to cope with the situation they are facing (Tanis, 2008). Further, mobile devices for data collection and interventions in real life settings have been used before (Bernhardt et al., 2009; Gerber, Stolley, Thompson, Sharp, \& Fitzgibbon, 2009). Thus, a chat group in a real life setting may serve as a useful way to evaluate individuals' thoughts about their eating behavior and to investigate situation-specific CHBs.

\section{Aim of the present study}

The study's aim was to investigate the role of CHBs for two different eating behaviors: fruit and vegetable consumption and eating unhealthy snacks. A mixed method approach was chosen for both eating behaviors separately. To assess the association between 
CHBs and the two eating behaviors, the quantitative analysis investigated the predictive value of CHBs over and above standard motivational and volitional constructs of the HAPA. To analyze situation-specific CHBs for both eating behaviors in the context of pursuing an eating goal, with a qualitative analysis, group messages from smartphone chat groups were rated. This approach was applied to expand existing knowledge about CHBs in order to understand barriers of health behavior change.

\section{Method}

The study was approved by the Faculty of Arts and Social Sciences of the University of Zurich and was carried out in accordance with the ethical guidelines of the Helsinki Declaration (World Medical Association, 2001).

\section{Study design}

This study was part of a larger randomized controlled trial on the effects of social support groups on healthy eating (see Inauen et al., 2017). The study was designed to address individuals who wanted to eat a healthier diet. All participants were randomly assigned to four experimental groups in a $2 \times 2$ study design (different eating goals vs. intervention conditions). Eating goals included either increasing fruit and vegetable consumption (fruit and vegetable condition) or eating fewer unhealthy snacks (unhealthy snack condition). Intervention conditions contained either a social support or a control condition. In the social support condition, participants joined smartphone chat groups with other study participants. The purpose of the smartphone chat groups was creating a social environment that supports the participant in pursuing their eating goals. Control group participants did not join smartphone chat groups. The four experimental groups are illustrated in Figure 1. For more information on study methods and on the intervention in particular, please see Inauen et al. (2017). 


\section{Procedure}

Individuals were eligible for study participation if they had not joined any weight loss programs, were not on a diet, were at least 18 years old, were fluent in German and owned a smart phone with internet access. Recruiting took place at the University of Zurich, through flyers, e-mailing lists and social networks. For study participation, individuals could choose between either receiving study credit or participating in two lotteries: 1) The chance to win one out of eight shopping vouchers (worth 100 US-Dollars) or 2) either a helicopter flight or a wellness weekend (worth 1000 US-Dollars).

All participants completed three measurement time points (see Figure 1). At Time 1, participants were invited to the lab, and obtained study information and a factsheet of health consequences about the respective eating goal. They signed the informed consent, completed the baseline questionnaire, and trained research assistants measured participants' weight and height. The intervention group received additional information about joining a smartphone chat group and hence provided their phone number. The aim of the intervention group was to exchange experiences about eating behavior and to provide social support. Three days after

Time 1, smartphone chat groups started and lasted for seven days. To ensure a minimum of social support for the intervention group, a trained female confederate of the experimenters attended the smartphone chat groups and acted as a participant. Thirty-two smartphone chat groups were created with a minimum of three participants and one confederate. One month (Time 2) and two months (Time 3) after Time 1, participants received an online follow-up questionnaire. Lastly, a debriefing was sent via email after study participation.

\section{Sample characteristics and participants flow}

For the quantitative part of the study, all participants from all four experimental groups were included in the analyses (see Figure 1). As the focus was not on the intervention effect, the intervention condition was included as a control variable for all further analyses. 
Figure 1 shows that of the 286 persons who signed up for a lab appointment, 50 did not show up, 2 did not consent to participate and 2 were excluded because their BMI was below 18 . The final sample $(N=232)$ included 177 women $(=76.3 \%)$ with an overall mean age of 27.3 years $(S D=8.5$ years, range: $18-63$ years $)$ and a mean body mass index $(\mathrm{BMI})$ of $23.5(S D=$ 4.1, range: 18-46.9). Difference statistics between the fruit and vegetable and the unhealthy snack condition are displayed in Table 1. One hundred-fifty-nine participants (68.5\%) reported being single, 69 (29.7\%) were married or in a committed relationship, five (1.5\%) were divorced, and 22 participants $(9.5 \%)$ reported having children. The majority of participants reported being university students $(65.9 \%), 46.1 \%$ reported having a job or an internship, $6.9 \%$ reported being doctoral students, $2.2 \%$ reported being a homemaker, also $2.2 \%$ being a pupil, $0.9 \%$ reported having no job and $0.4 \%$ being retired. $12.1 \%$ followed a vegetarian diet and $0.4 \%$ reported to be vegan. Sample characteristics for each condition are displayed in Table 1. Age, sex and BMI did not differ between conditions at Time 1.

In contrast to the quantitative analyses, the qualitative analyses only focus on participants in the intervention condition as they participated in smartphone chat groups (see Figure 1). The final sample in the smartphone chat groups $(n=79)$ included 54 women $(68.4 \%)$, with a mean age of $M_{\text {fruits and vegetables }}=26.26(S D=8.84)$ and $M_{\text {unhealthy snacks }}=28.09$ $(S D=10.05), t(76)=0.82, p=.413, d=0.19$, and mean BMI of $M_{\text {fruits and vegetables }}=23.12(S D$ $=3.36)$ and $M_{\text {unhealthy snacks }}=23.88(S D=3.92), t(77)=0.97, p=.334, d=0.22$.

A dropout analysis on the following main variables under study was conducted: CHBs, risk perception, outcome expectancy, self-efficacy, intention, action control, action planning, unhealthy snacks, fruits and vegetables, BMI, age and gender (see detailed dropout analysis in the supplementary material). For the unhealthy snack condition, there were no differences between completers and dropouts. For the fruit and vegetable condition, there is a tendency that self-efficacy appeared to be lower for dropouts $(M=6.18, S D=1.59)$ 
compared to completers $(M=6.86, S D=1.75), t(106)=$

$-1.97, p=.051, d=0.40$. Further, dropouts $(M=24.42, S D=3.72)$ were significantly

younger than completers $(M=28.90, S D=9.24, t(98.23)=-3.54, p=.001, d=0.58)$.

\section{Measures}

All items were phrased in two versions for the respective eating goal condition and presented in German. Scores ranged from "not at all true" (1) to "exactly true" (9). CHBs, motivational variables (risk perception, self-efficacy and outcome expectancies) and covariates were assessed at baseline (Time 1). Intention, action planning and action control were assessed at Time 2 and eating behavior at Time 3. Cronbach's Alpha were added to all measures with multiple items. Pearson product-moment correlations were reported for measures with two items.

Compensatory Health Beliefs. CHBs (adapted from Radtke et al., 2014) were measured with one item that captures overall compensation: "I can compensate for the negative effects of [my high-calorie snack consumption (e.g. cake or peanuts) / eating too few fruits and vegetables] by generally behaving healthily".

Risk perception. Risk perception (adapted from Scholz, Ochsner, Hornung, \& Knoll, 2013) was measured with three items: E.g. "To what extent do you think that eating [unhealthy snacks / too few fruits and vegetables] can harm your health?”. Reliability was good in both conditions: unhealthy snack condition $\alpha=.82$, and fruit and vegetable condition $\alpha=.81$.

Self-efficacy. Self-efficacy (adapted from Scholz et al., 2013) was measured with one item for fruit and vegetable consumption and two items for eating unhealthy snacks: E.g. "How certain are you that you can [avoid unhealthy snacks / eat fruits and vegetables] even if it will be difficult?". Bivariate correlation for unhealthy snacks was $r(122)=.48$. 
Outcome expectancies. Outcome expectancies (adapted from Scholz et al., 2013;

Scholz \& Berli, 2014) was measured with one item: "To what extent do you think that you will feel bad when eating [unhealthy snacks / low amount of fruits and vegetables]?”.

Intention. Intention (Inauen, Shrout, Bolger, Stadler, \& Scholz, 2016) was measured with two items: E.g. "For the next seven days, to what extent do you intend [to avoid unhealthy snacks / to eat more fruits and vegetables]?”. The bivariate correlation for unhealthy snacks was $r(70)=.77$ and for fruits and vegetables $r(69)=.80$

Action planning. Action planning (Allan, Sniehotta, \& Johnston, 2013) was measured with three items. E.g. "For the next seven days I have made a detailed plan [how to avoid unhealthy snacks / which kind of fruits and vegetables I am going to eat].” Reliability was high in both conditions: unhealthy snacks $(\alpha=.92)$ and fruits and vegetables $(\alpha=.92)$.

Action control. Action control (Scholz et al., 2013) was measured, with three items representing the three dimensions of action control: awareness of standards, self-monitoring, and self-regulatory effort (Sniehotta et al., 2005). An example item asked "In the last seven days have you monitored your intentions for [eating unhealthy snacks / your fruit and vegetables consumption?]”. Reliability was high in both conditions: unhealthy snack $\alpha=.84$ and fruit and vegetable $\alpha=.90$.

Eating behavior. Fruit and vegetable consumption and eating unhealthy snacks were measured with the same food frequency questionnaire (Strassburg, 2010). Participants were asked to imagine a typical day during the last week and to indicate their food consumption for different categories. Fruit and vegetable consumption was computed with the categories fruits and vegetables. Eating unhealthy snacks was computed with nine categories of unhealthy foods (the non-core foods of Kelly, King, Bauman, Smith, and Flood (2007), e.g. sweets, fast food). For each category, participants indicated whether they have eaten the described food for breakfast, lunch, dinner or between meals. Categories were summed in both conditions. 
The outcome was the number of fruit and vegetable servings (fruit and vegetable goal condition) or the number of unhealthy snacks (unhealthy snack goal condition) consumed on a typical day during the last week.

Covariates. Covariates included age, sex and body mass index (BMI, objectively measured). These covariates were hypothesized to be associated with eating behavior (Dehghan, Akhtar-Danesh, \& Merchant, 2011; Westenhoefer, 2005). Sociodemographic characteristics were assessed at Time 1 including the questions of being a vegetarian or a vegan.

CHB messages exchanged in smartphone chat groups. CHB messages included two categories: 1) compensation within eating behavior and 2) between different health behaviors. Definitions and descriptions of the categories were adapted from Radtke et al. (2014). Examples for compensation within eating behavior are "Eating no fruits and vegetables is ok as long as I am not eating any unhealthy snacks" or "I am allowed to eat a dessert if I skip a main meal". Examples for compensation between different health behaviors are "Eating fast food (e.g. burgers, kebab) is ok, as long as I exercise regularly" or "I can eat this chocolate now because I am going to exercise later".

\section{Data Analysis}

Quantitative analysis. To analyze the role of CHBs within the HAPA model, we conducted a saturated manifest path analysis (see Graham, 2003) with IBM AMOS 23.0 for each eating behavior separately. The model included CHBs, self-efficacy, outcome expectancies and risk perception measured at Time 1, intention, action planning and action control measured at Time 2 and eating behavior (fruit and vegetable consumption and eating unhealthy snacks) measured at Time 3. Further, the control variables age, BMI, sex, intervention condition (intervention vs. control group), baseline eating behavior at Time 1 and the identified missing mechanisms were included. 
To deal with missing data, a Full Information Maximum Likelihood (FIML) estimation method was used (Graham, 2009). This method considers the role of auxiliary variables that can reduce estimation bias and restore power due to missing data but does not affect parameter estimates, standard errors, or estimates of quality of fit (Graham, 2003, 2009). Due to the fact that AMOS does not report significance levels or confidence intervals when missing data occur, we analyzed indirect effects with the PROCESS macro in SPSS (Hayes, 2013). It is important to note that the PROCESS macro requires complete data and does not account for missing mechanisms (Hayes, 2016).

Outliers higher than 1.5 times the interquartile range were changed into the next closest value that was no outlier (Osborne \& Overbay, 2004; Rousseeuq \& Croux, 1993).

Qualitative analysis. To analyze situation-specific CHBs in chat group messages, two independent raters each classified two different $\mathrm{CHB}$ categories: $\mathrm{CHBs}$ within eating behavior and CHBs with other health behaviors. They received instructions with detailed information and examples of CHB categories (see Table 2). Raters attended a training session on how to rate chat group communication. They rated test messages several times and discussed categories in order to reach high agreement. Neuendorf (2002) recommends a twostep procedure for content analyses. Step 1 comprised a pilot rating and step 2 a final rating. For step 1, raters rated a pilot sample. As the pilot sample should not be included in the analysis (Neuendorf, 2002), the pilot sample included chat messages from participants who were excluded from the final sample (see study flow in Figure 1).

As interrater-reliability was low for the pilot sample, two new independent raters received revised instructions and a new training session based on discussed improvement from the first rating. For step 2, these new raters rated the final sample. Interrater agreement for both categories CHBs within eating behavior and CHBs with other health behaviors was 99\%. In line with recommendations (Lombard, Snyder-Duch, \& Bracken, 2002), we 
calculated Krippendorff's Alpha (Krippendorff, 2011) in addition to percent agreement. Interrater-reliability for CHBs within eating behavior was 0.67 and for CHBs with other health behaviors was 0.44 (Krippendorff's Alpha). Note, however, that Krippendorff's Alpha may become very small when only a few categories are rated, despite few mistakes being made by the raters (De Swert, 2012). In a consensus procedure with both raters, the final sample of messages for each category was defined.

\section{Results}

\section{Preliminary analyses}

Table 1 provides an overview of all main variables under study for both conditions including means, standard deviations, and group difference statistics. At baseline, individuals in the fruit and vegetable condition showed lower values for CHBs compared to the unhealthy snack condition. Values for self-efficacy were higher in the fruit and vegetable condition. At Time 1, participants in the fruit and vegetable condition ate $M=2.58$ $(S D=1.29)$ servings of fruits and vegetables on a typical day. This did not change significantly by Time $3(t=0.34, p=.738, d=0.05)$. In the unhealthy snack condition, participants consumed $M=1.33(S D=1.04)$ unhealthy snacks at Time 1 . Again, this did not change by Time $3(t=-.39, p=.700, d=0.05)$.

Table 3 presents inter-correlations between main study variables and control variables for both conditions. In the fruit and vegetable condition, CHBs negatively correlated with risk perception $(r(105)=-.25, p=.010)$ and in the unhealthy snack condition with action planning $(r(69)=-.33, p=.005)$.

\section{CHBs within the HAPA}

The path model for eating unhealthy snacks (Figure 2) shows a negative relation between CHBs and intention $(\beta=-.21, p=.033)$ and action planning $(\beta=-.22, p=.009)$. No association between $\mathrm{CHBs}$ and eating unhealthy snacks were found. The path model for fruit 
and vegetable consumption indicated no relation between CHBs and any of the HAPA variables (Figure 3). Additionally, results of the path models show more hypothesized relations between HAPA variables for the prediction of eating unhealthy snacks than for fruit and vegetable consumption. In both conditions, no indirect effects for CHBs on intention, action control, action planning or behavior were found.

\section{Situation-specific CHBs in smartphone chat groups}

Of total 608 messages written in the chat groups, introduction messages at the beginning of each chat group were excluded $(n=78)$. In total, 530 messages written by 79 participants in 28 groups were rated (fruit and vegetable condition $=245$; unhealthy snack condition $=85)$. The total number of messages written in groups ranged from $17-98$ $(M=40.57 ; S D=21.43)$. Number of messages written per person ranged from 1 to 29 $(M=7.69 ; S D=6.80)$.

Seven women $(=8.8 \%$ of all participants $)$ wrote in total eight $\mathrm{CHB}$ messages $(=1.5 \%$ of all messages). No men wrote any CHB message. Five messages were categorized in $\mathrm{CHBS}$ within eating behavior and three messages in CHBs with other health behaviors. Seven messages were written in the unhealthy snack condition and one in the fruit and vegetable condition.

For CHBs within eating behavior, participants reported that they compensated for their own unhealthy eating with less eating at a later time point. Participant 288 (age 27, BMI $=21.0$, unhealthy snack condition), for example, wrote: "I'm excited too... I had some cake for breakfast and then didn't have one for coffee time. It is some kind of self-deception isn't it?”. Or, participant 212 (age 19, BMI = 21.9, unhealthy snack condition), wrote: “...I have eaten a little [unhealthy snack at that moment] but not that much..." with the justification that eating a little bit is fine. Participant 211 (age 45, BMI $=21.3$, unhealthy snack condition) also reported to compensate for unhealthy eating with the idea that the next 
time she will do better: "Yes, [I have eaten] too much. When I am starting, I cannot eat only a little bit. In such situations, I always think that I can do better the next day...”. Participant 263 (age 28, BMI = 23.5, unhealthy snack condition) talked about her own unhealthy eating (cake) and justified it with the statement that she had not eaten any cake so far "Yes, but streusel cake! Hmm... Anyway, I hadn't had any [unhealthy] snacks so far...". Participant 103 (age 21, BMI = 23.8, fruit and vegetable condition) talked about doing better the next week "... from now up to a week I'll have some salads and fruits..."

For CHBs with other health behavior, participants talked about compensating for their unhealthy eating with physical exercises. Participant 212 (age 19, BMI = 21.9, unhealthy snack condition), for example, stated: “... and now I'm going to the gym to compensate for it again", and participant 234 (age 23, BMI = 24.0, unhealthy snack condition) said: "I don't experience eating snacks like chocolate bars as extremely unhealthy as long as I eat healthily in general and do enough exercise." One person justified her unhealthy eating with the statement that she already compensated for it with a sauna session (participant 243, age 56, $\mathrm{BMI}=23.2$, unhealthy snack condition): “...I just ate a lot from the dessert buffet but with no guilty conscience after a day in the sauna...".

\section{Discussion}

This study investigated the role of CHBs for two different eating behaviors with a mixed method approach. Quantitative findings showed that within the HAPA framework CHBs are significantly negatively related to intention and action planning only in the unhealthy snack condition but not in the fruit and vegetable condition. No significant relations were found between $\mathrm{CHBs}$ and the two eating behaviors.

The qualitative findings indicated that overall, individuals hardly communicate about situation-specific CHBs in group chats with strangers. If CHBs are included in chat groups, individuals communicate more often and more diversely when trying to reduce their 
unhealthy snack consumption compared to increasing their fruit and vegetable consumption. In the unhealthy snack condition, participants communicated CHB messages on the following topics: compensating unhealthy snack consumption with healthy eating at a later point in time; intending to do better another day; compensating for current unhealthy eating with previous healthy eating or another previously performed health behavior; and intending to do physical exercise in the future. In the fruit and vegetable condition, one individual communicated the intention to do better at a later stage. Overall, our study indicates a more prominent role for $\mathrm{CHBs}$ in the context of unhealthy snacks than of fruit and vegetable consumption.

These findings are in line with other research showing that fruit and vegetable consumption and eating unhealthy snacks underlie different explanatory mechanisms. For example, inhibitory self-control was a superior predictor for an undesired behavior and initiatory self-control a better predictor for a desired behavior indicating a difference in executive functions between fruit and vegetable consumption and eating unhealthy snacks (Allom \& Mullan, 2014; De Ridder, Lensvelt-Mulders, Finkenauer, Stok, \& Baumeister, 2011; Limbers \& Young, 2015). Further, implementation intentions are more effective to promote healthy eating than giving up unhealthy eating (Adriaanse, Vinkers, De Ridder, Hox, \& De Wit, 2011). Thus, a separate analysis of each behavior to better understand eating behaviors is essential.

Further, the $\mathrm{CHB}$ model claims that $\mathrm{CHBs}$ are activated only if individuals are facing a motivational conflict (Knäuper et al., 2004; Rabiau et al., 2006). Conflict situations can occur when exposed to food cues, as it has been shown that chocolate pictures activate the appetitive motivational system (Rodriguez, Fernandez, Cepeda-Benito, \& Vila, 2005). Recent literature demonstrated that food cue reactivity, such as craving, has been linked to foodrelated outcomes including eating and weight gain (Boswell \& Kober, 2016). We assume that 
people evaluate situations differently when exposed to food cues in terms of their eating goal. Eating less unhealthy snacks is an avoidance goal and thus, people need to inhibit the tendency to eat when exposed to a food cue. In contrast, eating more fruits and vegetables is an approach goal. Here, no inhibition of the behavior is needed, but the cue might be rather welcome in that it triggers the intended behavior. However, experimental studies on food cues are mainly based on unhealthy food such as the exposure to the smell of cookies (e.g. Larsen, Hermans, \& Engels, 2012). Therefore, future research may want to analyze whether CHBs are less activated due to a lower association between food cues of fruits and vegetables and conflicting situations.

Further, eating unhealthy snacks and fruit and vegetable consumption differ in terms of the reaction after showing the unintentional behavior (e.g. eating the chocolate bar or not eating a fruit). Only for eating unhealthy snacks, it may be interpreted as a real failure because for fruit and vegetable consumption, the behavior might still be shown at a later point in time during the day.

Our results that $\mathrm{CHBs}$ are related to the intention of unhealthy but not of healthy eating are in line with recent studies on CHBs (Radtke et al., 2014; Storm et al., 2016). However, there are studies finding no relation between CHBs and unhealthy eating (Radtke et al., 2014) and a significant negative association between CHBs and the intention for healthy eating (Fleig et al., 2015). In contrast to our study, those studies used different approaches to measure CHBs. In the present study, $\mathrm{CHBs}$ were measured with a general item in order to capture overall compensation. For a consistent and homogeneous measurement of CHBs, further improvements to assess CHBs are necessary as the original scale shows unsatisfying internal consistency (Radtke, Scholz, Keller, Perren, \& Hornung, 2013). Based on the present findings, future studies may compare a general CHB item with more specifically formulated 
items of compensatory beliefs, for example compensating for an unhealthy behavior with a healthy behavior at a later time point.

It is worth noticing that at Time 1, individuals reported significantly lower CHBs in the fruit and vegetable condition compared to the unhealthy snack condition. Thus, people may have stronger beliefs that they can compensate for the indulgence in an unhealthy behavior than for the failure to implement a healthy behavior. This is also emphasized by the results of this study showing a more prominent role of CHBs in the unhealthy snack condition compared to the fruit and vegetable condition. However, it needs to be noted that even if people use CHBs to justify their behavior, it might be difficult to measure them explicitly. The reason is that most people might not be aware of using CHBs as a selfregulatory strategy. Thus, future studies should add implicit measures to the study design (cf. Glock, Müller, \& Krolak-Schwerdt, 2013).

To the best of our knowledge, this is among the first studies that investigated CHBs with a qualitative approach showing, which CHBs people communicate when talking about their eating behavior. Although different compensatory beliefs were communicated by persons wanting to avoid unhealthy snacks, in total less than $2 \%$ of all message were CHB messages. This small number may have resulted because the focus of the mobile chat groups was on social support for successful eating behavior change, which might not include sharing compensatory beliefs about health behaviors. Further, previous studies asked people directly about their CHBs (Kaklamanou et al., 2013; Knäuper et al., 2004), which might be another explanation for the higher levels of CHBs reported than observed in natural behavior. It is also possible that people generate CHBs, but they do not communicate them to others. Or it could be that they might talk about CHBs with close others, but not with strangers in a chat group setting as in this study. There is evidence that people share more information when they feel close to the other persons and when they think that the exchange of information 
stays between the two persons (Wiese et al., 2011). For a valid assessment of people's beliefs, future studies should attempt to answer such questions by comparing different settings or social groups and investigate how group communication between strangers can be stimulated to reach higher interpersonal closeness. However, in the qualitative part, this study set out to examine whether there are different compensatory statements for unhealthy snacks compared to fruits and vegetables. This aim could not be met due to the low frequency of such statements in the data.

Further, it should be noted that contrary to previous findings for fruit and vegetable consumption (Schwarzer et al., 2008), risk awareness was the only significant predictor for intention and none of the HAPA variables were associated with fruit and vegetable consumption. In addition, we found a negative correlation between CHBs and risk awareness for fruit and vegetable consumption. Renner and Schwarzer (2005) state that risk awareness acts as a distal antecedent within the motivational phase and that risk awareness sets the stage for a process to think about consequences that may lead to intention. As our individuals were less aware of risks for low fruits and vegetables consumption at T1 compared to the unhealthy snack condition, they may have profited more from information about health consequences at $\mathrm{T} 1$.

Contrary to the assumed relation, there was a negative correlation between selfefficacy and intention in the unhealthy snack condition (see Table 3). Further, participants in the unhealthy snack condition reported significantly lower self-efficacy compared to participants in the fruit and vegetable condition. Thus, one potential explanation for this unexpected negative association could be that with regard to this particular behavior, people with very high intentions to avoid snacking are rather relying their intentions on positive outcome expectancies than on their self-efficacy. In fact, especially in the challenging area of avoiding one's unhealthy eating habits, people might have a history of negative experiences 
(which negatively impact self-efficacy), but still want to change their behavior due to assumed advantages (e.g., weight loss). Thus, especially those with higher intention might nonetheless have the lowest self-efficacy in this very special context.

Strengths of the present study include analyzing two randomly assigned distinct behaviors within the same health behavior domain and analyzing situation-specific CHBs in a real life setting. However, this study was not without limitations: The collected data were based on self-reported measures and there is evidence that under- and over-reporting can occur for energy intake (Black \& Cole, 2001; Rennie, Coward, \& Jebb, 2007). Future studies may measure eating behavior with stronger measures such as food diaries that allow for multiple entries per day (e.g. Gratton, Povey, \& Clark-Carter, 2007) or assessing eating behavior with objective measures such as a photo diary. Another limitation is that the results may be representative only for people who are highly motivated to change their eating behavior due to the recruitment strategy of this study. Thus, generalizability to people without strong intentions to change their diet may be limited. Further studies may investigate whether Compensatory Health Beliefs are stronger associated with intention and behavior for people who are less motivated to change their behavior.

\section{Conclusion}

To conclude, this is the first mixed-method study indicating a more prominent role of CHBs when aiming to eat fewer unhealthy snacks compared to aiming for eating more fruits and vegetables. The results suggest that especially people actively trying to eat fewer unhealthy snacks would benefit from an intervention to reduce $\mathrm{CHBs}$ to successfully change their eating behavior. Understanding the mechanisms of CHBs, especially how people think they can compensate for their eating behavior and when these thoughts appear, could be helpful for promoting a healthy diet. 


\section{Acknowledgements}

Neither this research nor the authors did receive any specific grant from funding agencies in the public, commercial, or not-for-profit sectors. Jenifer Inauen was employed at the University of Zurich during data collection. 


\section{Reference}

Adriaanse, M. A., Vinkers, C. D., De Ridder, D. T., Hox, J. J., \& De Wit, J. B. (2011). Do implementation intentions help to eat a healthy diet? A systematic review and metaanalysis of the empirical evidence. Appetite, 56(1), 183-193. https://doi.org/10.1016/j.appet.2010.10.012

Allan, J. L., Sniehotta, F. F., \& Johnston, M. (2013). The best laid plans: Planning skill determines the effectiveness of action plans and implementation intentions. Annals of Behavioral Medicine, 46(1), 114-120. https://doi.org/10.1007/s12160-013-9483-9

Allom, V., \& Mullan, B. (2014). Individual differences in executive function predict distinct eating behaviours. Appetite, 80, 123-130. https://doi.org/10.1016/j.appet.2014.05.007

Berli, C., Loretini, P., Radtke, T., Hornung, R., \& Scholz, U. (2014). Predicting physical activity in adolescents: The role of Compensatory Health Beliefs within the Health Action Process Approach. Psychology \& Health, 29(4), 458-474. https://doi.org/10.1080/08870446.2013.865028

Bernhardt, J. M., Usdan, S., Mays, D., Martin, R., Cremeens, J., \& Arriola, K. J. (2009). Alcohol assessment among college students using wireless mobile technology. Journal of Studies on Alcohol and Drugs, 70(5), 771-775. https://doi.org/10.15288/jsad.2009.70.771

Black, A. E., \& Cole, T. J. (2001). Biased over- or under-reporting is characteristic of individuals whether over time or by different assessment methods. Journal of the American Dietetic Association, 101(1), 70-80. https://doi.org/10.1016/S00028223(01)00018-9

Boswell, R. G., \& Kober, H. (2016). Food cue reactivity and craving predict eating and weight gain: a meta-analytic review. Obesity Reviews, 17(2), 159-177. https://doi.org/10.1111/obr.12354 
De Ridder, D. T., Lensvelt-Mulders, G., Finkenauer, C., Stok, F. M., \& Baumeister, R. F. (2011). Taking stock of self-control: A meta-analysis of how trait self-control relates to a wide range of behaviors. Personality and Social Psychology Review, 16(1), 76-99. https://doi.org/10.1177/1088868311418749

De Swert, K. (2012). Calculating inter-coder reliability in media content analysis using Krippendorff' Alpha. Retrieved from http://www.polcomm.org/wpcontent/uploads/ICR01022012.pdf. Archived at: http://www.webcitation.org/61WiNlu1L

Dehghan, M., Akhtar-Danesh, N., \& Merchant, A. T. (2011). Factors associated with fruit and vegetable consumption among adults. Journal of Human Nutrition and Dietetics, 24(2), 128-134. https://doi.org/10.1111/j.1365-277X.2010.01142.x

Dixon, J. B. (2010). The effect of obesity on health outcomes. Molecular and Cellular Endocrinology, 316(2), 104-108. https://doi.org/10.1016/j.mce.2009.07.008

Doytch, N., Dave, D. M., \& Kelly, I. R. (2016). Global evidence on obesity and related outcomes: An overview of prevalence, trends, and determinants. Eastern Economic Journal, 42, 7-28. https://doi.org/10.1057/eej.2014.37

Ernsting, A., Schwarzer, R., Lippke, S., \& Schneider, M. (2013). 'I do not need a flu shot because I lead a healthy lifestyle': Compensatory Health Beliefs make vaccination less likely. Journal of Health Psychology, 18(6), 825-836. https://doi.org/10.1177/1359105312455076

Festinger, L. (1962). A theory of cognitive dissonance (Vol. 2). Stanford, CA: Stanford University Press.

Fleig, L., Ngo, J., Roman, B., Ntzani, E., Satta, P., Warner, L. M.,. . Brandi, M. L. (2015). Beyond single behaviour theory: Adding cross-behaviour cognitions to the Health Action Process Approach. British Journal of Health Psychology, 20(4), 824-841. https://doi.org/10.1111/bjhp.12144 
Gerber, B. S., Stolley, M. R., Thompson, A. L., Sharp, L. K., \& Fitzgibbon, M. (2009).

Mobile phone text messaging to promote healthy behvaiours and weight loss maintenance:

a feasibility study. Health Informatics Journal, 15(1), 17-25.

https://doi.org/10.1177/1460458208099865

Glock, S., Müller, B. C. N., \& Krolak-Schwerdt, S. (2013). Implicit associations and compensatory health beliefs in smokers: exploring their role for behaviour and their change through warning labels. British Journal of Health Psychology, 18(4), 814-826. https://doi.org/10.1111/bjhp.12023

Graham, J. W. (2003). Adding missing-data-relevant variables to FIML-based structural equation models. Structural Equation Modeling, 10(1), 80-100. https://doi.org/10.1207/S15328007SEM1001_4

Graham, J. W. (2009). Missing data analysis: Making it work in the real world. Annual Review of Psychology, 60, 549-576. https://doi.org/10.1146/annurev.psych.58.110405.085530

Gratton, L., Povey, R., \& Clark-Carter, D. (2007). Promoting children's fruit and vegetable consumption: Interventions using the Theory of Planned Behaviour as a framework. British Journal of Health Psychology, 12(4), 639-650. https://doi.org/10.1348/135910706X171504

Hayes, A. F. (2013). Introduction to mediation, moderation, and conditional process analysis: A regression-based approach. Methodology in the social sciences. New York: The Guilford Press.

Hayes, A. F. (2016). The PROCESS macro for SPSS and SAS. Retrieved from http://www.processmacro.org/faq.html 
He, F. J., Nowson, C. A., \& MacGregor, G. A. (2006). Fruit and vegetable consumption and stroke: Meta-analysis of cohort studies. The Lancet, 367(9507), 320-326. https://doi.org/10.1016/S0140-6736(06)68069-0

Hu, D., Huang, J., Wang, Y., Zhang, D., \& Qu, Y. (2014). Fruits and vegetables consumption and risk of stroke: A meta-analysis of prospective cohort studies. Stroke, 45(6), 16131619. https://doi.org/10.1161/STROKEAHA.114.004836

Inauen, J., Bolger, N., Shrout, P. E., Stadler, G., Amrein, M. A., Rackow, P., \& Scholz, U. (2017). Using Support Group Messaging to Promote Healthy Eating in Daily Life: A Randomized Trial. Manuscript submitted for publication.

Inauen, J., Shrout, P. E., Bolger, N., Stadler, G., \& Scholz, U. (2016). Mind the gap? An intensive longitudinal study of between-person and within-person intention-behavior relations. Annals of Behavioral Medicine, 4(50), 516-522. https://doi.org/10.1007/s12160016-9776-x

Kaklamanou, D., Armitage, C. J., \& Jones, C. R. (2013). A further look into Compensatory Health Beliefs: A think aloud study. British Journal of Health Psychology, 18(1), 139154. https://doi.org/10.1111/j.2044-8287.2012.02097.x

Kelly, B., King, L., Bauman, A., Smith, B. J., \& Flood, V. (2007). The effects of different regulation systems on television food advertising to children. Australian and New Zealand Journal of Public Health, 31(4), 340-343. https://doi.org/10.1111/j.17536405.2007.00083.x

Knäuper, B., Rabiau, M., Cohen, O., \& Patriciu, N. (2004). Compensatory Health Beliefs: Scale development and psychometric properties. Psychology \& Health, 19(5), 607-624. https://doi.org/10.1080/0887044042000196737

Krippendorff, K. (2011). Computing Krippendorff's alpha reliability. Departmental papers. Retrieved from http://repository.upenn.edu/asc_papers/43 
Kronick, I., Auerbach, R. P., Stich, C., \& Knäuper, B. (2011). Compensatory beliefs and intentions contribute to the prediction of caloric intake in dieters. Appetite, 57(2), 435438. https://doi.org/10.1016/j.appet.2011.05.306

Larsen, J. K., Hermans, R. C. J., \& Engels, R. C. M. E. (2012). Food intake in response to food-cue exposure. Examining the influence of duration of the cue exposure and trait impulsivity. Appetite, 58(3), 907-913. https://doi.org/10.1016/j.appet.2012.02.004

Limbers, C. A., \& Young, D. (2015). Executive functions and consumption of fruits/ vegetables and high saturated fat foods in young adults. Journal of Health Psychology, 20(5), 602-611. https://doi.org/10.1177/1359105315573470

Lock, K., Pomerleau, J., Causer, L., Altmann, D. R., \& McKee, M. (2005). The global burden of disease attributable to low consumption of fruit and vegetables: Implications for the global stretegy on diet. Bulletin of the World Health Organization, 83(2), 100-108. Retrieved from http://www.scielosp.org/pdf/bwho/v83n2/v83n2a09.pdf. Archived at:http://www.webcitation.org/61WjEUawK

Lombard, M., Snyder-Duch, J., \& Bracken, C. C. (2002). Content analysis in mass communication: Assessment and reporting of intercoder reliability. Human Communication Research, 28(4), 587-604. https://doi.org/10.1111/j.14682958.2002.tb00826.x

Neuendorf, A. N. (Ed.). (2002). The contenct analysis guidebook. London: Sage Publications.

Osborne, J. W., \& Overbay, A. (2004). The power of outliers (and why researchers should always check for them). Retrieved from http://PAREonline.net/getvn.asp?v=9\&n=6. Archived at: http://www.webcitation.org/61W19rUDq

Rabiau, M., Knäuper, B., \& Miquelon, P. (2006). The eternal quest for optimal balance between maximizing pleasure and minimizing harm: The Compensatory Health Beliefs 
model. British Journal of Health Psychology, 11, 139-153.

https://doi.org/10.1348/135910705X52237

Radtke, T., Inauen, J., Rennie, L., Orbell, S., \& Scholz, U. (2014). Trait versus state: Effects of dispositional and situational Compensatory Health Beliefs on high-calorie snack consumption. Zeitschrift für Gesundheitspsychologie, 22(4), 156-164.

https://doi.org/10.1026/0943-8149/a000125

Radtke, T., Kaklamanou, D., Scholz, U., Hornung, R., \& Armitage, C. J. (2014). Are dietspecific Compensatory Health Beliefs predictive of dieting intentions and behaviour? Appetite, 76, 36-43. https://doi.org/10.1016/j.appet.2014.01.014

Radtke, T., Scholz, U., Keller, R., \& Hornung, R. (2012). Smoking is ok as long as I eat healthily: Compensatory Health Beliefs and their role for intentions and smoking within the Health Action Process Approach. Psychology \& Health, 27, 91-107. https://doi.org/10.1080/08870446.2011.603422

Radtke, T., Scholz, U., Keller, R., Perren, S., \& Hornung, R. (2013). German-language version of the Compensatory Health Belief scale: Assessing its psychometric properties. Zeitschrift für Gesundheitspsychologie, 21, 159-166. https://doi.org/10.1026/0943$8149 / \mathrm{a} 000100$

Renner, B., \& Schwarzer, R. (2005). The motivation to eat a healthy diet: How intenders and nonintenders differ in terms of risk perception, outcome expectancies, self-efficacy, and nutrition behavior. Polish Psychological Bulletin, 36(1), 7-15. Retrieved from http://nbnresolving.de/urn:nbn:de:bsz:352-opus-72632

Rennie, K. L., Coward, A., \& Jebb, S. A. (2007). Estimating under-reporting of energy intake in dietary surveys using an individualised method. The British Journal of Nutrition, 97(6), 1169-1176. https://doi.org/10.1017/S0007114507433086 
Rice, R. E. (2006). Influences, usage, and outcomes of internet health information searching: multivariate results from the pew surveys. International Journal of Medical Informatics, 75(1), 8-28. https://doi.org/10.1016/j.ijmedinf.2005.07.032

Rodriguez, S., Fernandez, M. C., Cepeda-Benito, A., \& Vila, J. (2005). Subjective and physiological reactivity to chocolate images in high and low chocolate cravers. Biological Psychology, 70(1), 9-18. https://doi.org/10.1016/j.biopsycho.2004.10.001

Rousseeuq, P. J., \& Croux, C. (1993). Alternatives to the median absolute deviation. Journal of the American Statistical Association, 88(424), 1273-1283. https://doi.org/10.2307/2291267

Scholz, U., \& Berli, C. (2014). A dyadic action control trial in overweight and obese couples (DYACTIC). BMC Public Health, 14, 1321. https://doi.org/10.1186/1471-2458-14-1321

Scholz, U., Ochsner, S., Hornung, R., \& Knoll, N. (2013). Does social support really help to eat a low-fat diet? Main effects and gender differences of received social support within the Health Action Process Approach. Applied Psychology: Health and Well-Being, 5(2), 270-290. https://doi.org/10.1111/aphw.12010

Schwarzer, R. (2008). Modeling health behavior change: How to predict and modify the adoption and maintenance of health behaviors. Applied Psychology, 57(1), 1-29. https://doi.org/10.1111/j.1464-0597.2007.00325.x

Schwarzer, R., Schütz, B., Ziegelmann, J. P., Lippke, S., Luszczynska, A., \& Scholz, U. (2008). Adoption and maintenance of four health behaviors: Theory-guided longitudinal studies on dental flossing, seat belt use, dietary behavior, and physical activity. Annals of Behavioral Medicine, 33(2), 156-166. https://doi.org/10.1007/BF02879897

Sniehotta, F. F., Scholz, U., \& Schwarzer, R. (2005). Bridging the intention-behaviour gap: Planning, self-efficacy, and action control in the adoption and maintenance of physical 
exercise. Psychology \& Health, 20(2), 143-160.

https://doi.org/10.1080/08870440512331317670

Storm, V., Reinwand, D., Wienert, J., Kuhlmann, T., De Vries, H., \& Lippke, S. (2016). Brief report: Compensatory Health Beliefs are negatively associated with intentions for regular fruit and vegetable consumption when self-efficacy is low. Journal of Health Psychology, 1-7. https://doi.org/10.1177/1359105315625358

Strassburg, A. (2010). Ernährungserhebungen: Methoden und instrumente. Ernährungs Umschau, 8, 422-430. Retrieved from https://www.ernaehrungs-umschau.de/printartikel/11-08-2010-eu-0810-ernaehrungserhebungen-methoden-und-instrumente/. Archived at: http://www.webcitation.org/61W1KxJH7

Tanis, M. (2008). Health-related on-line forums: What's the big attraction? Journal of Health Communication, 13(7), 698-714. https://doi.org/10.1080/10810730802415316

Taylor, C., Webb, T. L., \& Sheeran, P. (2014). 'I deserve a treat!: ': Justifications for indulgence undermine the translation of intentions into action. British Journal of Social Psychology, 53(3), 501-520. https://doi.org/10.1111/bjso.12043

Verhoeven, A. A., Adriaanse, M. A., De Vet, E., Fennis, B. M., \& De Ridder, D. T. (2015). It's my party and I eat if I want to. Reasons for unhealthy snacking. Appetite, 84, 20-27. https://doi.org/10.1016/j.appet.2014.09.013

Wang, P.-Y., Fang, J.-C., Gao, Z.-H., Zhang, C., \& Xie, S.-Y. (2016). Higher intake of fruits, vegetables or their fiber reduces the risk of type 2 diabetes: A meta-analysis. Journal of Diabetes Investigation, 7(1), 56-69. https://doi.org/10.1111/jdi.12376

Westenhoefer, J. (2005). Age and gender dependent profile of food choice. In I. Elmadfa (Ed.), Diet Diversification and Health Promotion (pp. 44-51). Basel: Karger Medical and Scientific Publishers. 
Wiese, J., Kelley, P. G., Cranor, L. F., Dabbish, L., Hong, J. I., \& Zimmerman, J. (2011). Are you close with me? Are you nearby? Investigating social groups, closeness, and willingness to share. Retrieved from http://www.cs.cmu.edu/afs/cs/Web/People/jasonh/publications/ubicomp2011-relationshipsharing-final.pdf. Archived at: http://www.webcitation.org/6lWlRMogi

Wing, R. R., \& Phelan, S. (2005). Long-term weight loss maintenance. American Society for Clinical Nutrition, 82(1), 222. Retrieved from http://ajcn.nutrition.org/content/82/1/222S.long. Archived at: http://www.webcitation.org/61WlpT2xE

World Health Organization. (2014). Global status report on noncommunicable diseases (Vol. 2014). Retrieved from http://apps.who.int/iris/bitstream/10665/148114/1/9789241564854_eng.pdf. Archived at: http://www.webcitation.org/61Wm7cTJ0

World Medical Association. (2001). World medical association declaration of Helsinki: Ethical principles for medical research involving human Subjects. Bulletin of the World Health Organization, 4(79), 373. Retrieved from https://www.ncbi.nlm.nih.gov/pmc/articles/PMC2566407/. Archived at: 


\section{Tables and Figures}

Table 1. Summary of sample characteristics and main study variables for unhealthy snack and fruit and vegetable condition.

\begin{tabular}{|c|c|c|c|c|c|c|c|c|c|}
\hline \multirow[b]{2}{*}{ Variables } & \multicolumn{2}{|c|}{ US $(n=122)$} & \multicolumn{2}{|c|}{$\mathrm{FV}(n=106)$} & \multicolumn{5}{|c|}{ Test } \\
\hline & $M$ & $S D$ & $M$ & $S D$ & $t$ & $\chi^{2}$ & $d f$ & $p$ & $d$ \\
\hline Age (years) & 27.3 & 8.9 & 27.3 & 8.0 & -0.01 & & 229 & .999 & 0.00 \\
\hline Women (\%) & 79.8 & - & 72.9 & - & & 1.55 & 1 & .214 & - \\
\hline Body mass index & 23.3 & 4.0 & 23.7 & 4.3 & -0.74 & & 230 & .460 & 0.10 \\
\hline $\begin{array}{l}\text { Compensatory } \\
\text { Health Beliefs }\end{array}$ & 6.0 & 2.4 & 4.6 & 2.4 & 4.42 & & 229 & $<.001$ & 0.58 \\
\hline Risk perception & 5.9 & 1.9 & 5.5 & 1.7 & 1.97 & & 230 & .051 & 0.22 \\
\hline $\begin{array}{l}\text { Outcome } \\
\text { expectancies }\end{array}$ & 5.3 & 2.3 & 5.8 & 2.4 & -1.61 & & 227 & .109 & 0.21 \\
\hline Self-efficacy & 4.9 & 2.0 & 6.6 & 1.8 & -7.00 & & 230 & $<.001$ & 0.89 \\
\hline Intention & 5.6 & 2.2 & 5.4 & 2.2 & 0.39 & & 142 & .694 & 0.09 \\
\hline Action Planning & 3.5 & 2.4 & 2.8 & 2.0 & 1.87 & & 142 & .064 & 0.32 \\
\hline Action Control & 3.1 & 1.9 & 3.5 & 1.9 & -0.96 & & 142 & .339 & 0.21 \\
\hline $\begin{array}{l}\text { Fruit and vegetable } \\
\text { consumption }\end{array}$ & 2.1 & 1.3 & 2.5 & 1.3 & -1.78 & & 138 & .077 & 0.31 \\
\hline $\begin{array}{l}\text { Eating unhealthy } \\
\text { snacks }\end{array}$ & 1.3 & 1.0 & 1.2 & 0.7 & 0.39 & & 118 & .701 & 0.12 \\
\hline
\end{tabular}

Note: US = Unhealthy snack condition FV = Fruit and vegetable condition; Age, gender, body mass index, Compensatory Health Beliefs, risk perception, outcome expectancies and self-efficacy were measured at Time 1; Intention, action planning and action control were measured at Time 2; Fruit and vegetable consumption and unhealthy snacks were measured at Time 3. 
Table 2. Compensatory Health Beliefs coding scheme: Rater instructions with definitions and examples.

\begin{tabular}{|c|c|c|}
\hline Category & Definition & Examples \\
\hline $\begin{array}{l}\text { Compensation } \\
\text { within eating } \\
\text { behavior }\end{array}$ & $\begin{array}{l}\text { The unhealthy behavior can be compensated for with a } \\
\text { healthy behavior at a later point in time, e.g. eating } \\
\text { chocolate now and e.g. eating fruits and vegetables } \\
\text { later. } \\
\text { The justification to show an unhealthy behavior by } \\
\text { compensating for it with a healthy behavior (Radtke et } \\
\text { al., 2012) } \\
\text { The person beliefs that a unhealthy behavior (= eating } \\
\text { unhealthily or not eating healthily) can be compensated } \\
\text { for or neutralized if she/he shows a healthy behavior } \\
\text { (= eating healthily or not eating unhealthily; adapted } \\
\text { from Knäuper et al., 2004) } \\
\text { The focus lies on the compensation for the target } \\
\text { behavior (attention! Please consider relevant condition). }\end{array}$ & $\begin{array}{l}\text { Eating no fruits and vegetables is ok as long as I am not } \\
\text { eating any unhealthy snacks. } \\
\text { Eating unhealthy snacks is ok as long as I eat fruits and } \\
\text { vegetables. } \\
\text { I can eat whatever I want at night, as long as I have not eaten } \\
\text { anything during the day. } \\
\text { I am allowed to eat a dessert if a skip a main meal. } \\
\text { If I have eaten an unhealthy snack / no fruits and vegetables } \\
\text { today, it's okay, because I can change my eating behavior } \\
\text { tomorrow. } \\
\text { I am eating this unhealthy snack now. Later, I really won't eat } \\
\text { any more unhealthy snacks. } \\
\text { I am eating this unhealthy snack now but later I will eat a } \\
\text { little less. } \\
\text { I am eating this unhealthy snack now but later I will only eat } \\
\text { salad. } \\
\text { I am eating this unhealthy snack now but starting tomorrow, I } \\
\text { am going to eat less. } \\
\text { Eating cake from time to time is okay, as long as I don't eat } \\
\text { high-calorie dessert. }\end{array}$ \\
\hline $\begin{array}{l}\text { Compensation } \\
\text { between } \\
\text { different health } \\
\text { behaviors }\end{array}$ & $\begin{array}{l}\text { Same as for compensation within eating behavior, but } \\
\text { compensation for other health behaviors, e.g. sport, } \\
\text { exercise etc. } \\
\text { The focus lies on the compensation for the target } \\
\text { behavior (attention! Please consider relevant condition). }\end{array}$ & $\begin{array}{l}\text { Eating fast food (e.g. burgers, kebab) is okay, as long as I } \\
\text { exercise regularly. } \\
\text { I will eat this chocolate now because I am going to exercise } \\
\text { later. }\end{array}$ \\
\hline
\end{tabular}


Table 3. Intercorrelations between variables for fruit and vegetable consumption (below diagonal) and unhealthy snack consumption (above diagonal).

\begin{tabular}{|c|c|c|c|c|c|c|c|c|c|c|c|}
\hline & 1 & 2 & 3 & 4 & 5 & 6 & 7 & 8 & 9 & 10 & 11 \\
\hline 1. Compensatory Health Beliefs & & -.03 & -.13 & -.00 & -.19 & $-.33^{* *}$ & .18 & .05 & -.13 & -.02 & -.02 \\
\hline 2. Risk perception & $-.25^{*}$ & & $.29^{* *}$ & -.13 & .08 & .10 & .20 & .04 & .10 & -.02 & .04 \\
\hline 3. Outcome expectancies & -.07 & $.44^{* * *}$ & & -.10 & $.39^{* *}$ & .21 & $.24^{*}$ & -.02 & -.06 & $-.29^{* *}$ & $.31^{* *}$ \\
\hline 4. Self-efficacy & .11 & -.08 & -.03 & & $-.26^{*}$ & -.18 & -.04 & -.10 & -.10 & -.11 & -.16 \\
\hline 5. Intention & -.02 & $.48^{* * *}$ & .21 & .03 & & $.67^{* * *}$ & $.38^{* *}$ & -.09 & .05 & -.11 & $.32^{* *}$ \\
\hline 6. Action Planning & -.02 & .16 & .10 & .01 & $.44^{* * *}$ & & $.33^{* *}$ & -.06 & .04 & -.02 & .03 \\
\hline 7. Action Control & -.04 & $.27^{*}$ & .18 & -.04 & $.50^{* * *}$ & $.56^{* * *}$ & & -.24 & -.02 & .12 & -.15 \\
\hline 8. Behavior & -.09 & .04 & .15 & .09 & .15 & .22 & $.30^{*}$ & & .19 & $-.25^{*}$ & .01 \\
\hline 9. Body mass index & .18 & -.07 & $-.19^{*}$ & .18 & .01 & -.01 & .03 & -.01 & & $.33^{* * *}$ & $-.22^{*}$ \\
\hline 10. Age & -.13 & -.06 & -.13 & -.06 & .01 & .13 & .04 & .05 & $.33^{* * *}$ & & $-.21^{*}$ \\
\hline 11. Gender & -.04 & $.20^{*}$ & -.01 & -.01 & $.42^{* * *}$ & .23 & $.33^{* *}$ & .19 & -.01 & .09 & \\
\hline
\end{tabular}

Note: Gender: $0=$ male , $1=$ female; Number of participants for Time $1: n=107$ in the fruit and vegetable condition and $n=124$ in the unhealthy snack condition; for Time 2: $n=70$ in the fruit and vegetable condition and $n=71$ in the unhealthy snack condition; for Time $3 n=68$ in the fruit and vegetable condition and $n=61$ in the unhealthy snack condition; Behavior $=$ fruit and vegetable consumption in the fruits and vegetables condition and unhealthy snacks in the unhealthy snacks condition; * $p<0.05$. ** $p<0.01$. *** $p<0.001$ 
Running head: COMPENSATORY HEALTH BELIEFS IN EATING BEHAVIOR CHANGE

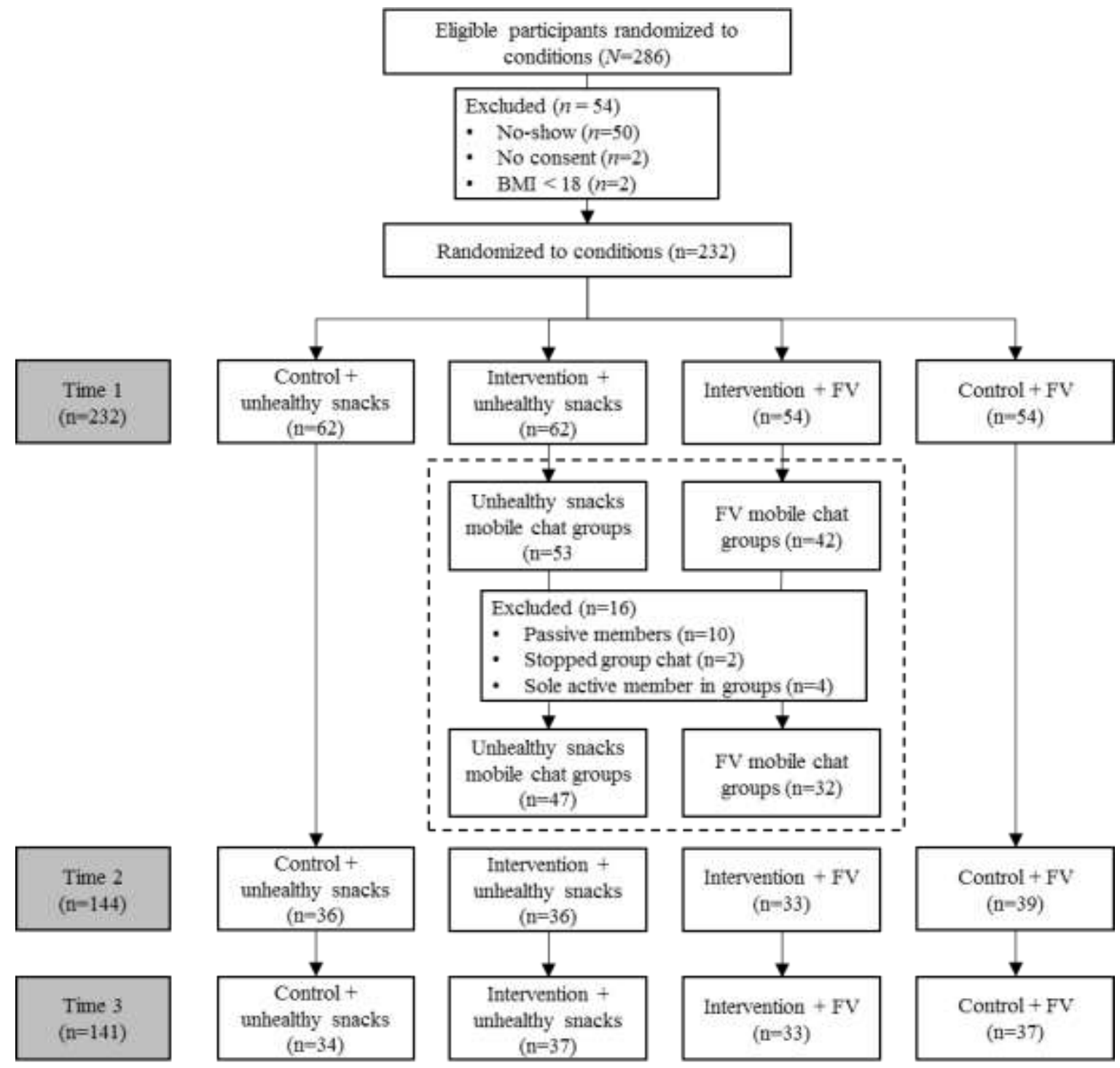

Figure 1. Study flow chart. FV = Fruit and vegetable condition. Study flow differs from Inauen et al. (2017) due to different exclusion criteria. 


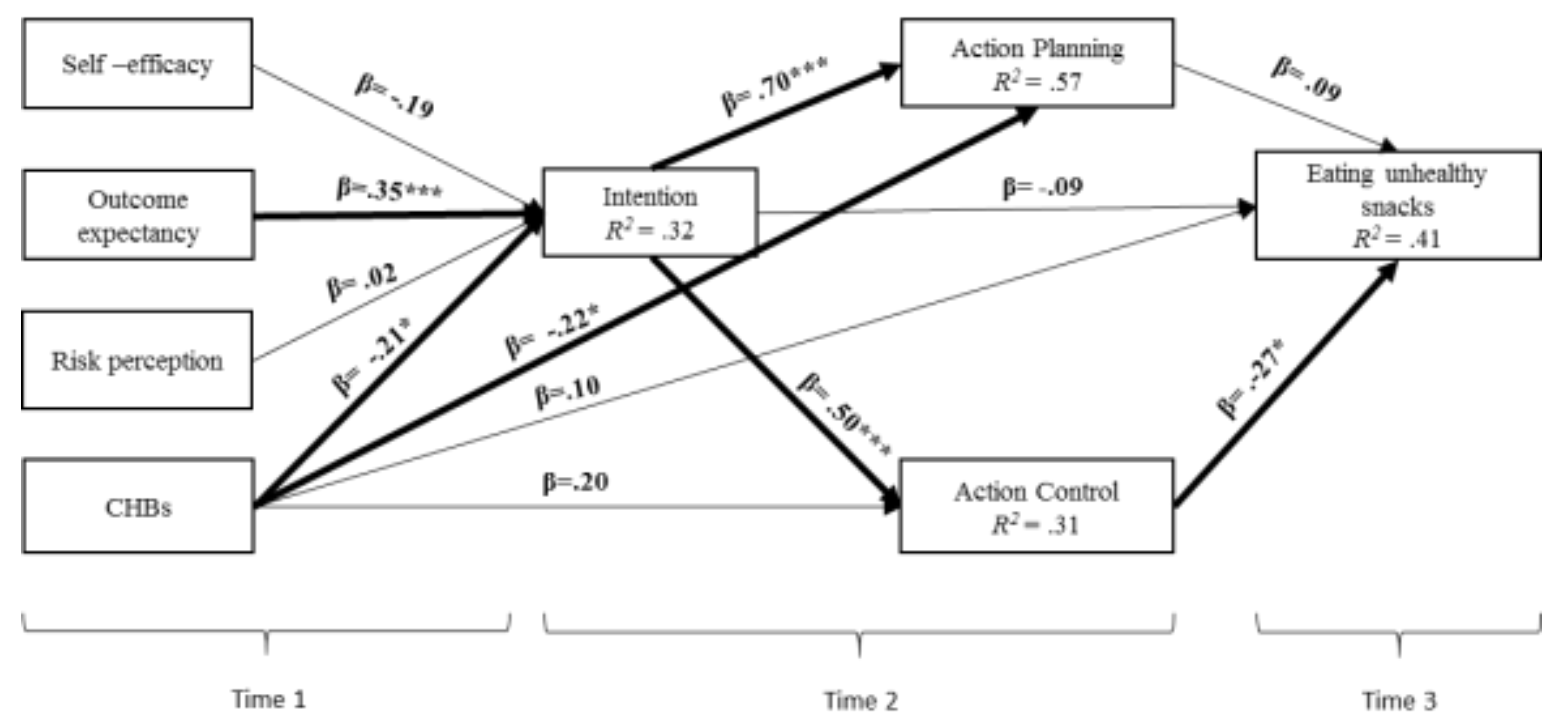

Figure 2: Saturated path model for the prediction of eating unhealthy snacks; $n=124$; Bold lines indicate significant regression weights; Intention, action planning, action control and eating unhealthy snacks was adjusted for age, BMI, gender and the intervention; Eating unhealthy snacks was additionally adjusted for baseline behavior; Correlations between variables are not displayed; $* p<0.05 . * * p<0.01 . * * * p<0.001 . R^{2}=$ adjusted $R^{2}$. 


\section{CHANGE}

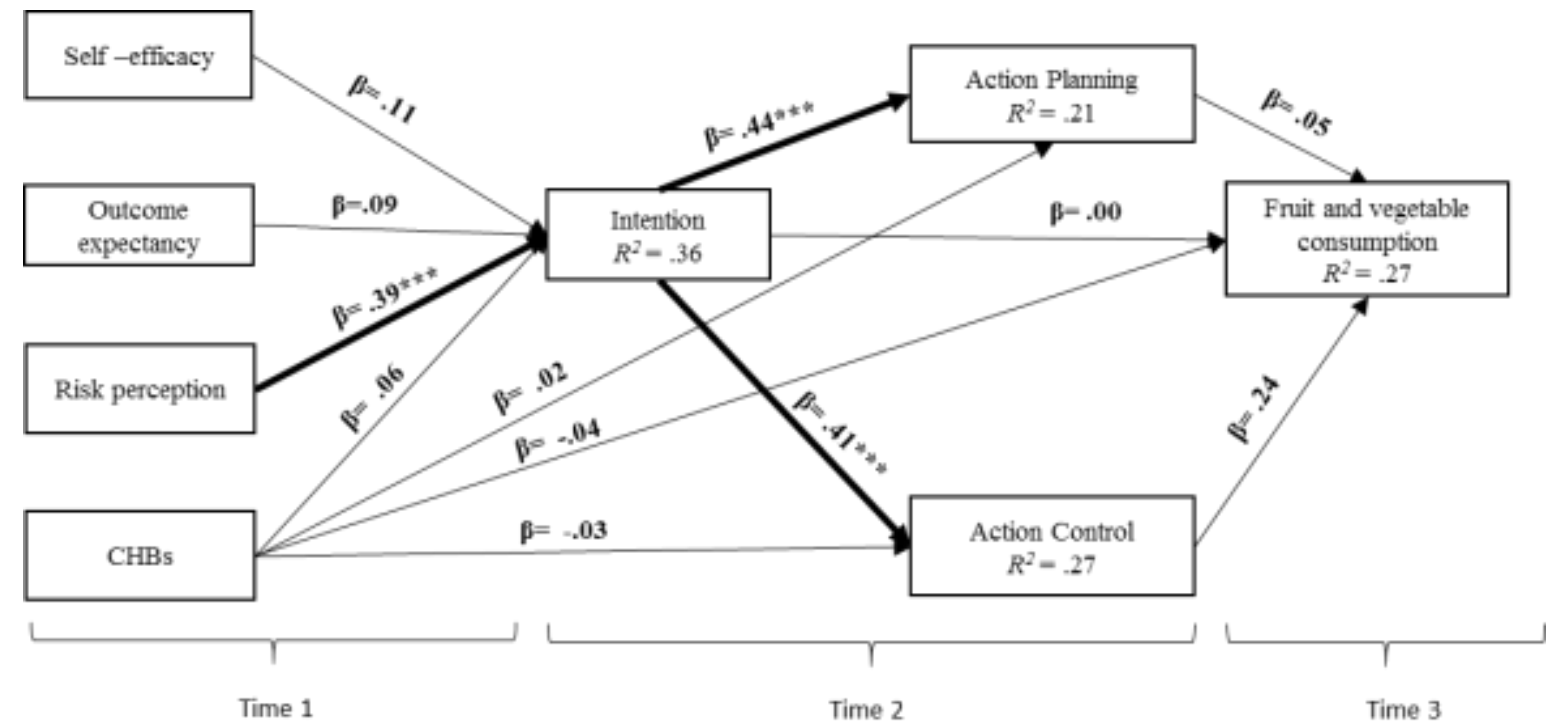

Figure 3: Saturated path model for predicting fruit and vegetable consumption; $n=108$; Bold lines indicate significant regression weights; Intention, action planning, action control and fruit and vegetable consumption was adjusted for age, BMI, gender and the intervention; Fruit and vegetable consumption was additionally adjusted for baseline behavior;

Correlations between variables were allowed, but are not displayed; $* p<0.05 . * * p<0.01$. *** $p<0.001 . R^{2}=$ adjusted $R^{2}$. 